\title{
Weaving virtual service networks into regional cities: "nurture the body here, and offer the mind anywhere" - anecdotes from the Coffs Harbour community forums to minimise carbon usage and maximise regional innovation
}

\author{
$\underline{\text { Seemann, K. }} .{ }^{1,2}$ \\ ${ }^{1}$ Senior Academic, Southern Cross University \\ ${ }^{2}$ Adjunct Associate Professor, Curtin University Sustainability Policy (CUSP) Institute \\ Email: kseemann@scu.edu.au
}

\begin{abstract}
Almost all cities around the world are looking for ways to ease the pressure upon them where caused by a migratory drift from rural and regional areas into to the economic and service hubs that they offer. At the same time, rural and regional areas are losing the idyllic appeal of a "country" or "ruralcoastal" lifestyle due to issues related mostly to access to services and employment security. During 2011, the community of Coffs Harbour engaged in a series of public forums to discuss ideas for how to attract more professional people into the area (especially people with capacity to build further employment), support small to medium enterprises and enhance the region as a 'smart city' conscious of sustainability. The rhetoric and promise of building very high speed internet services was well promoted in all the forums given that Coffs Harbour is now one of two regional location in Australia that has received accelerated roll out funding to enhance access to fast broad band services. However, the potential of broadband technology is a topic that has not yet found a way to strategically weave its value into the fabric and general awareness of the local economy and community. This paper presents annotations that may be described as 'pre-conceptual/pretheory' on the issue of expressed perceptions noted by the author during the community forum events held at Coffs Harbour. It draws specific attention to the issue of the city's future and the promise of superfast broadband services.
\end{abstract}

Keywords: National broadband network, rural sustainability, decentralisation, lifestyle, virtualised economy, internet, the web, regional cities 


\section{INTRODUCTION}

The Coffs Harbour region has embarked on an effort to proactively grow its services and facilities in a direction that promotes both sustainability as well as attract the professional sectors, service sectors, and small to medium enterprises looking to exploit early market presence with the substantial roll out of super fast broadband technologies funded by the National Broadband Network (NBN) (Australian Federal Government, 2011). It is hoped that this strategy to attract new capabilities into rural cities will help both enhance local economic activities, as well as transform the region towards a more sustainable place for people to enjoy. Being very early in the process of its plan, the first impressions are offered here by the author drawing on observations gleaned from authentic participation in a series of local community forums about the future direction of Coffs Harbour.

Planning is underway by the author to investigate the series of Coffs Harbour Community Forums hosted by Southern Cross University, the Coffs Harbour City Council and the Coffs Coast Advocate. The Forums aim to facilitate public discussion and ultimately provide a road map for the future of the region to feed into the city's 2030 vision (Coffs Harbour City Council, 2011). One of the goals of the planned study is to assess the community forum process as a means for building and measuring collegial confidence in community development. The study will also analyse the role of a higher education institution in such a process. Recent publications show, however, that while there are many reports in the literature of community engagement projects, evaluative analyses are limited (Hart \& Northmore, 2011). Holland (2009) refers to the complexity and confusion around accurate measurement of the beneficial outcomes and impacts of collaborative work such as community-university engagement. For this reason, this initial paper is cast in the context of emerging authentic annotations, and so should be noted as 'pre-conceptual or pre-theory in status, but nevertheless, also authentic as a critical reflection of observed comments gleaned by the author while a participant in the community forums and group gatherings to date.

In New South Wales (NSW), the State Government has initiated a policy direction that shifts prior governance strategies from centralised services mostly located in Sydney, to decentralised services spreading government investment to rural towns of best fit. Coffs Harbour, located on the gateway to the mid-north coast region of NSW, recently embraced the news that "16 NSW fisheries research jobs will be relocated to Coffs Harbour from Cronulla [Sydney] as part of the O'Farrell Government's 'decade of decentralisation"' (Deans, 2011). The move by the State Government to decentralise its services to logically located rural cities should provide a regional boost of investment based on the normal multiplier effect of staff and family migrations to those rural areas; this includes increased injection of cash and justified demand for other services such as retail, health and education services.

With the 'push' policy rolling out by the State to migrate some of its services from urban city hubs to rural ones, and the 'pull' policy of the Federal Government of connecting rural cities to super fast broadband services, one critical issue is the basis upon which together these two policies may best serve some rural cities more than others, and whether those cities are also best placed to attract professional and knowledge intensive vocationally skilled people into their local economy away from the urban centres from which they came.

To facilitate the optimum exploitation of the NBN roll out, the Coffs Harbour City Council has drawn upon its 2030 planning process to guide the region's 'readiness' to both accommodate the potential of the NBN, but also to examine other needs for the region (Coffs Harbour City Council, 2011; Rudd, 2011).

\section{REVERSING URBANISATION: ANECDOTES FROM PUBLIC FORUMS IN COFFS HARBOUR}

The Coffs Harbour community has been engaged in a series of public discussions in open forum sessions. These forums have been facilitated by the Coffs Harbour City Council, Southern Cross University, The Advocate (a local news paper) and business and community groups. The issue of how to exploit the NBN remained a high priority topic amongst the community. Being mostly oriented towards fibre to households, the optical cable solution is also perceived as the most energy efficient and effective means to connect households on a speed and volume basis, and so the preferred technology when it comes to the carbon footprint of broadband networks (Australian Federal Government, 2011). A specific objective raised in community forums around Coffs included not only building local knowledge and skills in how to exploit the NBN, but equally, how to draw in and attract a new demographic to the Coffs Region of people and businesses that are already capable of exploiting the technology. There was an expressed view that one emerging market is for knowledge based produces and services that benefit from fast quality transfers of valued commodities of information. Examples of such forms of information commodities include the transfer 
of x-ray film images between the clinic where the film was created and the home or high-resolution mobile devices (such as the iPad2) that may be in the hands of general practitioners and possibly also the client. Other examples of high value information commodities may include those from the health services, education and the arts and creative industries such as crisp audio video imagery of live two way home care monitoring, and crisp video conferencing, festival and gallery markets online, and development of quality education media. Further, the capacity of NBN is thought to be well placed to facilitate local manufacturing design services where complex engineering, product and architectural building designs could be created in the Coffs region, and sent to high technology semi-automated manufacturing centres elsewhere, or vice-versa. This new opportunity to enable a knowledge and innovation commodity economy is one that would foster a shift in the demographics of the Coffs coast region towards more professionals and highly skilled individuals. Collectively the Coffs Region hopes to exploit the NBN in order to raise the general level of health and economic growth of its region; and by so doing reduce the carbon emissions on a per head basis associated with rural travellers and couriers.

\subsection{Attracting and locally growing new knowledge based skills in rural communities}

One key point raised during the community forums in the Coffs Harbour region, under the Local City Council's 2030 planning processes, is the need to retain, attract and grow more professionals and high skill individuals into the city's region. The basis for this aspiration is both to raise local economic activity, as well as generate a shift in the local socio-economic profile of the Coffs coast: from relatively high unemployment and low skill jobs market, to more people in employment and more in higher knowledge skills market.

When broadband was introduced across the United Kingdom (UK) in recent years, the uptake of the roll out was immediately observed as problematic. Consistent with both the early adoption patterns of many innovations there was a natural initial suspicion of the value of new technologies. The promise of high speed broadband attracted mixed reactions from the community. Williams (2011b) noted in the case of the UK that the hardware "roll-out suggests...that a national broadband network is purely a technical matter ... [but] 'roll-up' speaks to the need to understand that success is achieved when the passive notion of enabling success is replaced by an active reaching out to people to actually use this new tool - with a myriad of unforeseen consequences for well-being, as much as increases in Gross Domestic Product (GDP)" (Williams, 2011b, p. 54).

Observations by the author of the way the local Coffs Harbour community have thus far responded to the broadband roll out, is that the demands to learn to exploit it are not yet well understood. Further, those who do understand would need more than fast broadband to want to relocate and generate market responsive work into this region. The implication is, that the demographic that would be skilled to exploit the NBN would also seek a range of quality of life services in the region that they currently enjoy in or near capital cities. These include attention to health, education, especially the presence of a good university for those with young families, and a rich cultural and ecologically desirable environment. There was a view that knowledge skilled professional may also hold expectations for themselves and their children to have access to higher educational services. Other draw card expectations voiced included access to quality health and transport services and a culturally rich and diverse lifestyle preferably in ecologically sustainable and attractive climates. Some of these drivers of lifestyle associated with place are evident in Coffs Harbour but perhaps not so obvious at first glance. Coffs Harbour has an aged profile; it has long been regarded as an idyllic retirement location due to a fair degree to the temperate conditions and local ecology: it is also a very popular family holiday escape region for the same reasons. It has a base hospital, with a university research campus on its grounds (University of New South Wales Rural Health Research). It has a suite of core State and Federal Government services, and health practitioners, a rail service, and modern well designed airport with regular access to Australia's cities. In its surrounds Coffs has the ingredients to connect professionals to creative arts industries, though this area has also been raised in forums as a growth issue, with calls for a major arts and events venue to be included in the region's planning processes.

In contrast to the push to attract a new demographic to the region that is knowledge commodity skilled, is an equally strong voice for exploiting the NBN for social inclusion and social equity reasons. The Mid North Coast was highlighted in forums as also accommodating socially disadvantaged groups including Aboriginal, unemployed and under employed sectors of the community with limited success in accessing educational and health services through traditional offerings. This issue was seen as another key area that the NBN can help support with services of health care into houses as well as enhanced educational participation into the homes of people otherwise excluded for various reasons. 
To summarise these observations from community conversations, there appears to be set of key idea that are both "pull" oriented in their affect to bring in knowledge savvy demographics, a push effect that appears to be more policy based to relocate government services to the region from the city, as well as a 'grow it locally' effect to address better social inclusion outcomes from the NBN. These factors may be summarised to include the following areas where the NBN roll out could find it can demonstrate its greatest uptake value.

- Creative industries: enhance a rich and diverse creative, and cultural arts sector

- Higher education (university) services for future investment of 'stay value' in the region

- On the above, the community response is to see a local university with a culture and reputation for pursuing cutting edge knowledge and innovation rather than standardised content

- Excellent health services, including 'access' to specialists and local clinics

- Facilitate social inclusion and equity of services into households of greatest need

- A very fast virtual infrastructure that opens up the benefits of a knowledge commodity using high resolution design and data file transfers in not only health and education services, but also design and innovation in manufacturing services.

\subsection{Exploiting the natural advantage}

Many of the observations noted through the community forums have predominately focussed on education, services and economics. However, there remain a few background issues to add to the framework of what makes a rural city most attractive to knowledge commodity professionals and businesses; the lifestyle quality of the rural location itself. As noted above, one indicator of where people want to live is where they aspire to move to either relax on holiday or even for early retirement. While such location characteristics are arguably subjective, the mid north coast region of Australia has for decades been targeted for both its quality of climate and ecology as highly desirable locations for living. Locations of natural advantage are those where people would like to live, that offer as some forum participants voiced, the best of the city and the ecology of the rural coast. Factors noted included:

- clean air and water

- temperate climates, and

- $\quad$ convenient access to services; for example, regular flights to anywhere else.

\section{KEY IDEAS: "NURTURE THE BODY AND SOUL, WHILE OFFERING THE MIND ANYWHERE"}

Strategies to pick modest economic rural locations that have very high human habitat appeal appear to be emerging in the community forums as what may drive the value of the region, and the benefits of the NBN roll out. This paper presented a collection of views gathered from the community forums that suggest more research is required to clarify if some of the expressed drivers for growing the Coffs Coast region are indeed as key as they are perceived to be in order to both exploit the NBN as well as sustainability grow the regions economy in a productive and socially inclusive manner.

One interesting idea worthy of specific research is whether investing in the basic human need to nurture people's physical and social wellbeing in highly desirable and ecologically healthy locations with NBN services are key factors for growing such rural locations. This possible policy framework may be examining the hypothesis that broadband investment should consider the effect of its uptake when placed natural built advantaged locations that are well placed to "nurture the body and soul, while offering the mind anywhere"; these are places that combine ecologically healthy human habitation with highly virtualised liveability infrastructure.

\section{CONCLUSION}

This paper may be regarded as 'pre-conceptual', in that it explores the community conversations and annotations emerging from a series of open public discussions in the Coffs Coast region. The open discussions emerged during the city's 2030 forums since 2008 and continue today through public forum events in a collaboration between the Coffs Harbour City Council, the local campus of Southern Cross University and the local media. Put simply, there appears to be a thesis that ought now be contested, and that is that the best fit locations for maximum rural city choice for broadband investment are those around Australia that well satisfy all or most of the following selection criteria. There rural cities:

- Where people like to both retire and holiday 
- Host a higher education (university) services for future investment of 'stay value' in the region

○ Especially where the local university pursues a culture and reputation for cutting edge knowledge and innovation rather than standardised content.

- Access to excellent health services, including 'access' to specialists and local clinics

- Where people can engage in rich and diverse creative arts and lifestyles

- Have access to very fast virtual infrastructure, including free open wifi access in social and cultural gathering spaces that enables enhanced communications, and a knowledge and innovation commodity experience

- Clean air and water, and a temperate climates

- Conveniently located to services; for example, regular flights to anywhere else, and ideally easy and alternative local transport facilities and services.

There is an opportunity to progress such observations to a more developed and structured research agenda. In particular, a national search for rural city locations that rank best along the proposed criteria listed above. It is hypothesised that the rural cities that best fit the above criteria are also likely to be the best fit locations for seeding new growth economies based on attracting professionals and high skill people who can engage in a knowledge and innovation based commodity market, as well as a virtually enhanced and supplemented service industry.

\section{ACKNOWLEDGEMENTS}

The author would like to thank the very insightful and detailed feedback offered by the two blind peer reviewers for this concept paper. Their thoughts have helped the paper lift its quality and position the work for a more formal opportunity into the future.

\section{REFERENCES}

Australian Federal Government (2011). Rod Tucker on fibre to the home energy savings. Retrieved from http://www.nbn.gov.au/media-centre/videos/rod-tucker-on-fibre-to-the-home-energy-savings/

Coffs Harbour City Council (2011). Coffs Harbour 2030. Retrieved 10th October, 2011, from http://www.coffsharbour.nsw.gov.au/Coffs-And-Council/our-future/Pages/coffs-harbour-2030.aspx

Deans, M. (2011). Jobs relocated to boost economy. The Coffs Coast Advocate. Retrieved from http://www.coffscoastadvocate.com.au/story/2011/09/30/city-jobs-relocated-to-boost-economy/

Hart, A., and Northmore, S. (2011). Auditing and evaluating university-community engagement: Lessons from a UK case study. Higher Education Quarterly, 65(1), 34-58.

Holland, B. A. (2009). Will it last? Evidence of institutionalization at Carnegie classified community engagement institutions. New Directions for Higher Education, Fall(147), 85-98.

Rudd, D. (2011). The NBN expained in Coffs Harbour. Retrieved from http://www.nbn.gov.au/mediacentre/videos/nbn-explained-coffs-harbour/

Williams, T. (2011a). Connecting communities: The impact of broadband on communities in the UK and its implecations for Australia. Huawei Technologies Co. Ltd., Melbourne.

Williams, T. (2011b). Connecting Communities. The impact of broadband on communities in the UK and its implecations for Australia. White Paper. Hauwei, Sydney. 